\title{
Osteonecrosis in HIV: A Case-Control Study
}

\author{
Anita N. Scribner, *†Paolo V. Troia-Cancio, §Bruce A. Cox, * $\ddagger$ David Marcantonio, \\ *Faruk Hamid, *†Philip Keiser, "Marilyn Levi, I[Brady Allen, \#Kevin Murphy, \\ $* \S$ Richard E. Jones, and *†Daniel J. Skiest
}

*The University of Texas Southwestern Medical Center, Dallas; †Department of Medicine, $\ddagger$ Department of Radiology, and §Department of Orthopedic Surgery, University of Texas, Dallas; "ID Associates, St. Paul Medical Center, Dallas; q[Aesculapius Medical Health Group, Dallas, Texas; and \#Sierra Infectious Diseases, Reno, Nevada, U.S.A.

Osteonecrosis (also known as avascular necrosis [AVN] or aseptic necrosis) results in cell death of various bone components, including hematopoietic fat marrow and mineralized tissue. Osteonecrosis is not a specific disease entity, but rather the final common pathway

Address correspondence and reprint requests to Daniel J. Skiest, Division of Infectious Diseases, The University of Texas Southwestern Medical Center, 5323 Harry Hines Boulevard, Dallas, TX 75390-9113, U.S.A.; email: dskies@mednet.swmed.edu.

Dr. Scribner is in private practice in Longview, Texas, U.S.A.

Manuscript received March 22, 2000; accepted June 1, 2000. of several conditions, most of which lead to impairment of the blood supply to the bone. Osteonecrosis was diagnosed in 35,000 inpatients in 1997 in the United States and accounts for approximately $5 \%$ of hip arthroplasties $(1,2)$. It occurs significantly more frequently in men than women (3). Most cases occur in those younger than 50 years of age $(3,4)$.

Multiple etiologies may result in osteonecrosis (3-6). These can be divided into traumatic and nontraumatic types. Traumatic causes include fractures or dislocations. The list of nontraumatic causes of osteonecrosis is 
lengthy and includes Gaucher's disease, hemoglobinopathies, radiotherapy, corticosteroid administration, Cushing's disease, diabetes mellitus, renal dialysis, hyperlipidemia, excessive alcohol intake, fatty liver, hyperuricemia and gout, osteomalacia, pancreatitis, WeberChristian disease, pregnancy, renal transplantation, systemic lupus erythematosus and other connective tissue disorders, thrombophlebitis, and tumors. No association with known risk factors has been noted in approximately $8 \%$ to $20 \%$ of osteonecrosis cases $(3,5)$.

Recently, osteonecrosis has been reported in patients with HIV infection (7-20). In general, these reports have consisted of small series, were uncontrolled, and did not include detailed information about the patients such as CD4 cell count, HIV viral load, and antiretroviral use (including protease inhibitors [PIs]). It has been suggested that HIV itself is an independent risk factor for osteonecrosis. Due to the apparent recent increase in incidence in osteonecrosis in HIV-infected populations, and the well-described metabolic complications of PIs, it has been suggested that osteonecrosis is a complication of highly active antiretroviral therapy, specifically PIs $(7,17,20)$. To address some of these issues, we conducted a case-control study of osteonecrosis cases diagnosed in Dallas since 1984.

\section{METHODS}

All cases of osteonecrosis in HIV-infected patients, diagnosed from 1984 through 1998 at Parkland Health and Hospital System, a 1000-bed county teaching hospital in Dallas County, Texas were reviewed. Cases were found from the following sources: review of codes from the ninth edition of the International Classification of Diseases, Injuries, and Causes of Death, the Parkland HIV case registry (a standardized database that records information on all HIV-positive patients seen at Parkland Hospital) and a query of all providers of HIV care at Parkland Hospital. An additional 9 cases culled from the records of HIV treating physicians in private practice in Dallas County were also reviewed.

The medical records of thirty potential cases were reviewed by one of the authors. In addition, all cases were reviewed by an independent radiologist. Inclusion as a case of osteonecrosis required evidence of both a clinical and radiographic diagnosis of osteonecrosis alone or with a pathologic diagnosis of osteonecrosis. Two cases not meeting the above criteria were included among the cases inasmuch as radiographic reports indicated a diagnosis of osteonecrosis and they had a clinical diagnosis of osteonecrosis, but the radiographs could not be located for rereview. After review, 5 cases were excluded. One potential case was found to be a coding error and 4 others did not meet radiographic criteria for osteonecrosis when reviewed by the radiologist.

Using computerized randomization, 2 controls were selected for each case patient. Controls were selected from HIV-antibody positive patients seen in the same clinic or office on the same day the case patient was diagnosed with osteonecrosis or as inpatients for the 2 patients who were diagnosed as inpatients.

Charts of cases and controls were reviewed and data extracted using a standardized data collection form. Information collected by chart review included demographic data, dates of diagnosis of osteonecrosis and HIV infection, risk factors for HIV, possible risk factors associated with osteonecrosis, number and location of involved joints, and laboratory data (CD4 cell count, HIV viral load, white blood cell count [WBC], hemoglobin, platelet count, red blood cell sedimentation rate [ESR], antinuclear antibodies [ANA], aspartate aminotransferase [AST], alanine aminotransferase [ALT], total bilirubin, albumin, international normalized ratio [INR], partial thromboplastin time [PTT], prothrombin time [PT], anticardiolipin antibodies, antiphospholipid antibodies, uric acid, testosterone level, amylase, lipase, total triglycerides, and total cholesterol). In addition, medications (including antiretrovirals and corticosteroids) prescribed to the patient at the time of diagnosis were recorded.

Patients were classified as having a history of alcohol abuse if concern about condition was noted in the chart by the patient's clinician. Corticosteroid use was considered a risk factor if the patient was taking prednisone $\geq 30 \mathrm{mg} /$ day, or an equivalent steroid dose, for at least 1 month before onset of symptoms. Patients previously diagnosed with a deep venous thrombosis or other hypercoaguable state were classified as hypercoaguable. Patients were classified as having hyperlipidemia as a risk factor if they had a serum triglyceride level greater than 400 $\mathrm{mg} / \mathrm{dl}$ or serum total cholesterol greater than $250 \mathrm{mg} / \mathrm{dl}$. Patients with a prior history of pancreatitis, gout, or end-stage renal disease were classified with these disorders, respectively. Patients previously noted to have osteopenia, with a history of pathologic fractures or vertebral collapse on radiographic studies were classified as having severe osteopenia as a risk factor. Laboratory results were recorded from random samples taken on the date of diagnosis. If no values were available from that time, preference was given to the latest value obtained prior to the diagnosis of osteonecrosis up to a period of 1 year previously.

The classification system developed by Steinberg et al. and modified by Resnick and Niwayama was used for radiographic staging of femoral osteonecrosis $(21,22)$. Briefly, this classification system uses six stages of osteonecrosis (stages 0-5) based on the degree of radiologic changes and measures the extent of involvement. Stage 0 is a normal or nondiagnostic radiograph. Stage 1 has normal radiographic findings but abnormal findings on bone scan or magnetic resonance imaging (MRI). Stage 2 comprises "cystic" and sclerotic changes. Stage 3 is subchondral collapse without flattening. Stage 4 demonstrates flattening of the femoral head. Stage 5 has joint narrowing alone or combined with acetabular changes.

Comparisons were made between cases and controls and evaluation for statistical significance was performed using $\chi^{2}$ or Fisher's exact test, where appropriate. A two-tailed $p$ value of .05 was considered significant. StatView 5.0 (SAS Institute, Cary, NC, U.S.A.) software was used for the statistical analysis. The multivariate analysis and linear by linear association were calculated using SPSS 8.0 software version 8 (Chicago, IL, U.S.A.).

\section{RESULTS}

Twenty-five cases of osteonecrosis were identified. Sixteen cases were diagnosed at Parkland Hospital and nine cases were diagnosed in the community. Two cases were diagnosed prior to 1996 (i.e., before introduction of highly active antiretroviral therapy [HAART]), whereas 23 cases were diagnosed in 1996 or later. Ten of the 25 cases were diagnosed in 1998 in the Parkland Hospital HIV clinic. In all, 2673 were patients seen in our clinic 
during 1998, for an estimated incidence of osteonecrosis for 1998 of $0.37 \%$.

Demographic characteristics of cases and controls are shown in Table 1. The gender, ethnic backgrounds, HIV risk categories, and mean age were reflective of the overall population with HIV infection in Dallas. No significant differences were noted among cases and controls in terms of age, race, or HIV risk category. All case patients were men whereas $16 \%$ of controls were women. Maleto-male sex was the most common HIV risk factor among cases and controls. Nineteen patients had at least one prior AIDS-defining illness prior at the time of osteonecrosis diagnosis.

The mean CD4 cell count (available in 22 case patients) was lower in osteonecrosis patients compared with control patients: 270 cells/ $\mu l$ (range, $1-786$ ) versus 340 cells/ $\mu$ l (range, 1-821), respectively. However, this difference did not reach statistical significance. The median HIV viral load (by Roche Amplicor polymerase chain reaction [Roche Molecular Systems, Branchburg, NJ, U.S.A.) in the 20 osteonecrosis patients with this information available was 1148 copies/ml compared with 1259 copies $/ \mathrm{ml}$ in the 42 controls for whom this information was available. The proportion of patients with an HIV viral load $<400$ copies/ml was similar in cases and controls: $30 \%$ of cases compared with $34 \%$ of controls, respectively.

A substantial delay transpired from time of the first complaint (as documented in the chart) until the diagnosis of osteonecrosis in most cases. The median number of days from time of the complaint to a diagnosis was 46 and the mean time to diagnosis was 125 days (range, 1-643 days). The most frequent complaint was pain,

TABLE 1. Demographic data

\begin{tabular}{|c|c|c|}
\hline & $\begin{array}{c}\text { Cases } \\
n=25\end{array}$ & $\begin{array}{l}\text { Controls } \\
n=50\end{array}$ \\
\hline Male & $25(100 \%)$ & $42(84 \%)$ \\
\hline Age $(y)$ & 40 & 39 \\
\hline \multicolumn{3}{|l|}{ Race $^{a}$} \\
\hline White & $14(58 \%)$ & $26(53 \%)$ \\
\hline Black & $8(29 \%)$ & $14(28 \%)$ \\
\hline Hispanic & $2(12 \%)$ & $9(18 \%)$ \\
\hline \multicolumn{3}{|l|}{ HIV risk category } \\
\hline Male-male sex & $17(68 \%)$ & $27(54 \%)$ \\
\hline Injecting drug use (IDU) ${ }^{b}$ & $4(16 \%)$ & $7(14 \%)$ \\
\hline Heterosexual sex & $1(4 \%)$ & $5(10 \%)$ \\
\hline Unknown & $3(12 \%)$ & $11(22 \%)$ \\
\hline $\begin{array}{l}\text { CD4 cell count (cells } / \mu \mathrm{l}) \text {, } \\
\text { median (mean) }\end{array}$ & $270(271)$ & $340(341)$ \\
\hline $\begin{array}{l}\text { Viral load }\left(\log _{10} \text { copies } / \mathrm{ml}\right), \\
\text { mean (median) }\end{array}$ & $3.06(3.45)$ & $3.10(3.39)$ \\
\hline
\end{tabular}

${ }^{a}$ Information not available for 1 patient in each group.

${ }^{b}$ Patients with IDU and a second risk factor are grouped under IDU (includes 7 patients). most often felt in the groin. All patients had at least one hip involved. Seventy-two percent of the patients had multiple joints involved, most frequently the contralateral hip (18 of 25), whereas 16\% (4 of 25) had shoulder involvement as well.

Of these patients, 24 had plain radiographs, 8 underwent MRI scanning, and 3 had technetium bone scans. (Several patients were examined using more than one radiographic modality.) Diagnosis was made by plain radiograph in 20 patients and by MRI in 4 patients. In 3 patients, plain radiographs were normal prior to diagnosis by another method, for example, MRI. Information on radiographic stage at the time of diagnosis was available in 22 patients. One patient presented with grade 0,2 presented with grade 1,7 with grade 2,6 with grade 3,3 with grade 4 , and 2 with grade 5 osteonecrosis. Information on the duration of symptoms before diagnosis was available in 18 patients. The mean time from the onset of symptoms to diagnosis was 84 days (median 36 days) in patients with grade 2 or less compared with 162 days (median 80 days) in patients with Grade 3 or greater, $(p=.38)$.

Most case patients had known risk factors for osteonecrosis. The most common risk factors among cases were hyperlipidemia (32\%), alcohol abuse (28\%), exogenous corticosteroids (12\%), and a hypercoaguable state $(12 \%)$. Less common risk factors included a history of pancreatitis, history of gout, and severe osteopenia (4\%). Of the three case patients who had received corticosteroids, 2 had received them for 4 months each. The duration of corticosteroid therapy in the third patient was unknown.

Although no individual osteonecrosis risk factor was statistically more prevalent in case patients, when compared with controls, cases were significantly more likely to have one or more established risk factors for osteonecrosis (Table 2). Of 25 case patients, 22 had at least one osteonecrosis risk factor compared with 24 of 50 controls (odds ratio [OR], 7.94; 95\% confidence interval [CI], 2.11-29.97). A correlation was found between number of risk factors and risk of osteonecrosis $(\eta=0.349 ; p=$ .003; Table 3).

Four case patients, but no controls, received megesterol acetate as an appetite stimulant before diagnosis of osteonecrosis, $p=.01$. Duration of treatment with megesterol acetate was 1 month each in 2 patients, intermittent usage over 5 years in 1 patient, and unknown in the remaining patient in that group.

Complete antiretroviral medication records were available in 24 of 25 cases and in 41 of 50 controls. No single nucleoside analogue or nonnucleoside reverse transcriptase inhibitor was associated with osteonecrosis. 
TABLE 2. Univariate analysis comparing osteonecrosis patients and controls by risk factors for osteonecrosis

\begin{tabular}{lcccc}
\hline & $\begin{array}{c}\text { Cases } \\
n(\%)\end{array}$ & $\begin{array}{c}\text { Control } \\
n(\%)\end{array}$ & p Value & $\begin{array}{c}\text { Odds ratio } \\
(95 \% \text { CI })\end{array}$ \\
\hline Hyperlipidemia & $8(32)$ & $12(24)$ & .58 & $1.49(0.52-4.31)$ \\
Corticosteroid use & $3(12)$ & $1(2)$ & .11 & $6.68(0.66-67.88)$ \\
Alcohol abuse & $7(28)$ & $6(20)$ & .56 & $1.56(0.51-4.74)$ \\
Pancreatitis & $4(16)$ & $4(8)$ & .43 & $2.19(0.50-9.61)$ \\
$\begin{array}{l}\text { Gout } \\
\text { Severe osteopenia }\end{array}$ & $1(4)$ & $0(0)$ & .33 & Undetermined \\
$\begin{array}{l}\text { Hypercoaguable } \\
\quad \text { state }\end{array}$ & $3(12)$ & $0(0)$ & .33 & Undetermined \\
$\begin{array}{l}\text { End stage renal } \\
\quad \text { disease }\end{array}$ & $0(0)$ & $2(4)$ & .55 & Undetermined \\
Any risk factor & $22(88)$ & $24(48)$ & .002 & $7.94(2.11-29.97)$ \\
\hline
\end{tabular}

Some patients had multiple risk factors. CI, confidence interval

Nineteen of 24 (79\%) osteonecrosis patients were taking one or more PIs at time of osteonecrosis diagnosis whereas 31 of $41(76 \%)$ controls were taking PIs, $p>.99$. Patients with osteonecrosis compared with controls were more likely to be receiving saquinavir ( 10 of 25 versus 2 of 48 , respectively; $p=.0002$ ) or the combination of saquinavir-ritonavir ( 5 of 25 versus 2 of 48 , respectively; $p=.038)$. In a multivariate logistic model receipt of saquinavir $(\mathrm{OR}, 14.7 ; p<.05)$ and having any osteonecrosis risk factor $(\mathrm{OR}, 7.4 ; p<.05)$ remained significantly associated with osteonecrosis. No other PI was associated with osteonecrosis.

The mean triglyceride level was $333 \mathrm{mg} / \mathrm{dl}$ (range, $32-864 \mathrm{mg} / \mathrm{dl}$ ) in the 21 patients with random values available compared with $281 \mathrm{mg} / \mathrm{dl}$ (range, $58-840 \mathrm{mg} /$ $\mathrm{dl})$ in 38 controls in whom this value was available $(p=$ .36). Mean total cholesterol level was similar in cases and controls, $192 \mathrm{mg} / \mathrm{dl}$ (range, $84-322 \mathrm{mg} / \mathrm{dl}$ ) versus $205 \mathrm{mg} / \mathrm{dl}$ (range, $117-366 \mathrm{mg} / \mathrm{dl}$ ), respectively $(p=$ $.47)$.

The ESR was elevated at the time of osteonecrosis diagnosis in all 5 patients in whom it was available (mean $45 \mathrm{~mm} /$ hour). Antinuclear antibodies were negative in all 6 case patients who had this information recorded. No significant abnormalities were noted for any of the following tests: WBC, hemoglobin, platelets,

TABLE 3. Comparison of osteonecrosis risk factors between cases and controls

\begin{tabular}{lrr}
\hline & Cases & Controls \\
& $n=25(\%)$ & $n=50(\%)$ \\
\hline $\begin{array}{l}\text { No. of osteonecrosis } \\
\text { risk factors }\end{array}$ & \\
0 & $3(12)$ & $26(52)$ \\
1 & $17(68)$ & $19(38)$ \\
2 & $5(20)$ & $5(10)$ \\
\hline$p=.003 ; \eta=0.349$. &
\end{tabular}

AST, ALT, total bilirubin, albumin, total protein, or testosterone.

Anticardiolipin and antiphospholipid antibodies were elevated in the single patient in which they were performed. This patient was 1 of 3 patients with a history of deep venous thrombosis, who was also found to be homozygous for the Factor $\mathrm{V}$ Leiden mutation in addition to having elevated levels of PT and PTT. A specific etiology of deep venous thrombosis in the other 2 patients was not determined.

Seven patients underwent hip replacement, 5 patients underwent a core compression procedure ( 1 of whom later underwent hip replacement), and 14 patients were managed medically with limitation of weight bearing. Some of the latter group of patients also had corticosteroid injections in their bursae. Patients diagnosed at Parkland Hospital were more likely to be managed medically compared with patients diagnosed elsewhere: 12 of 16 versus 2 of 9 .

\section{DISCUSSION}

Since 1990, 58 cases of osteonecrosis in HIV-infected patients have been published (7-20). Our series adds significantly to the literature of osteonecrosis in HIVinfected individuals and is the first case-controlled study of osteonecrosis in HIV. In general, our series is similar to previously reported cases in terms of age and male predominance. We did not find age, HIV risk category, CD4 cell count, or HIV viral load to be associated with osteonecrosis.

The 1998 incidence of osteonecrosis in our clinic population was $0.37 \%$, which is greater than the estimated incidence of $0.135 \%$ in the general population; however, the two sets of incidence data were obtained by different methods. The latter figure is based on hospitalized patients and is likely an underestimate. Most cases in our study were diagnosed in the last year of the study, possibly indicating an increasing incidence of osteonecrosis. However, an equally plausible explanation for the predominance of recent cases in our study is underdiagnosis or misdiagnosis of osteonecrosis in the past due to lack of experience of HIV providers with this condition, as well as the effect of recall bias of recent cases.

In our series, the group of patients with osteonecrosis was significantly more likely to have established risk factors for osteonecrosis than the controls. In the nonHIV-infected population, risk factors can be identified in $80 \%$ to $92 \%$ of patients with osteonecrosis $(3,5)$. Of our cases, $88 \%$ had identifiable risk factors, which is greater than that reported in prior series of HIV-infected patients with osteonecrosis (47\%) and in agreement with series of 
osteonecrosis in HIV-negative individuals. The higher proportion of patients with risk factors in our series may reflect our study population or that we specifically looked for all possible osteonecrosis risk factors. Risk factors reported in prior series of osteonecrosis in HIV include hyperlipidemia in $24 \%$, corticosteroid use in $14 \%$, hypercoaguable state in $9 \%$ (including positive anticardiolipin or antiphospholipid antibodies), alcohol abuse in $9 \%$, history of radiation therapy in 3\%, pregnancy in 3\%, and gout in 3\% of patients (7-20). Most osteonecrosis patients in our series had risk factors known to be associated with this condition, most commonly hyperlipidemia (32\%), alcohol abuse (20\%), and corticosteroid use (12\%). Thus, although others have suggested that HIV infection itself is an independent risk factor for osteonecrosis, an alternative explanation is that certain osteonecrosis risk factors are more prevalent in HIV-infected patients.

Corticosteroids are a known risk factor for osteonecrosis and are frequently prescribed in HIV-infected patients. The 3 patients who received prednisone in our series were being treated for Crohn's disease, HIVrelated thrombocytopenia, and peripheral neuropathy/ chronic pain syndrome, respectively. In addition, 4 other patients were receiving megesterol acetate, which may have predisposed them to osteonecrosis. Megesterol acetate has glucocorticoid activity and has been reported to cause Cushing's syndrome (23-26). Gibert et al. have described 3 HIV-infected patients who developed osteonecrosis while receiving megesterol acetate (27). Because a substantial number of patients with HIV receive megesterol acetate for AIDS-associated wasting syndrome, HIV-treating clinicians should be aware of a possible association with osteonecrosis. Finally, 1 of our patients with osteonecrosis was taking large doses of dehydroepiandrosterone (DHEA), which may have predisposed him to the development of osteonecrosis.

Altered lipid metabolism has been recognized in patients with HIV infection. Hypertriglyceridemia, noted in HIV even before PIs, has become more prevalent in recent years, possibly because of PI therapy (28). It has been postulated that altered lipid metabolism results in emboli and infarcts in bone and that engorgement of marrow fat cells may lead to compression of bone vasculature/ischemia (3). Whether this mechanism leads to osteonecrosis in HIV remains to be determined.

Although the mean triglyceride level was higher in cases than controls, this difference was not statistically significant. It is possible that hypertriglyceridemia would be found to be an independent risk factor for HIVassociated osteonecrosis if more patients were included. In addition, we did not have any patients with marked hypertriglyceridemia, for instance, levels $>1000 \mathrm{mg} / \mathrm{dl}$ ). Marked hypertriglyceridemia, which has been associated with PI therapy, may be more likely to be associated with osteonecrosis.

Thromboembolic disease and hypercoaguable states are well described risk factors for osteonecrosis $(29,30)$. Alterations in coagulation with an increased tendency to thromboembolic disease have been described in HIVinfected patients $(31,32)$. Several mechanisms for a hypercoaguable state in HIV have been proposed including altered levels of protein $\mathrm{S}$ and the increased prevalence of anticardiolipin and antiphospholipid antibodies in HIV. A role for antiphospholipid antibodies in osteonecrosis associated with HIV has been suggested; however, evidence of this has only been present in a few reported cases $(8,12,19)$. Given that prevalence of anticardiolipin and antiphospholipid antibodies is so high in HIVinfected patients (50\%-92\%), the significance of these antibodies as a risk factor for thromboembolic events in HIV is unclear (33-36). Although 3 of our osteonecrosis patients had evidence of a hypercoagulable state, protein $\mathrm{C}$ and $\mathrm{S}$, anticardiolipin and antiphospholipid antibodies, and Factor V Leiden were not routinely measured in all patients. Therefore, we are unable to determine the significance of these conditions as an osteonecrosis risk factor.

Alcohol abuse is prevalent in our clinic population. The incidence of osteonecrosis in alcoholic populations ranges from $17 \%$ to $74 \%$. It is speculated that ethanol abuse and associated hyperlipidemia and fatty infiltration of the liver predispose to systemic fat embolism or intravascular coagulation.

In our study, a similar number of cases and controls received PIs. In a univariate analysis, receipt of saquinavir or the combination of ritonavir-saquinavir was associated with osteonecrosis; however, in multivariate analysis, only saquinavir remained significantly associated with osteonecrosis. This finding is of interest but is difficult to explain and should be interpreted with caution due to the relatively small numbers. We are not aware of any reports suggesting unique or more severe metabolic effects with saquinavir compared with other PIs. However, this association deserves further study in a larger cohort.

Others have suggested that PIs may cause osteonecrosis $(7,17,20)$. However, the cases reported were all diagnosed in the post-HAART era, when most HIV-positive patients received PI therapy. Thus, the high prevalence of PI usage in these series may simply reflect the population of HIV-positive patients in the era of HAART. Because no control groups were used in prior studies it was not possible to determine whether PIs were indepen- 
dently associated with the development of osteonecrosis. Most of our patients were receiving PIs; however, an equal proportion of our controls were too. Further arguing against the importance of PIs as a cause of osteonecrosis is that 37 cases of osteonecrosis in HIV were reported before introduction of PIs $(8-11,13-15,18,19)$. Thus, although we cannot exclude an association of osteonecrosis with use of PIs, we did not find PIs as a class to be significantly associated with the development of osteonecrosis.

Delay in the diagnosis of osteonecrosis was common in our cohort. The mean time from the onset of symptoms until diagnosis was 139 days. Patients with earlier disease (radiographic grade 2 or less) had a shorter (mean 84 days) but not statistically significant duration of symptoms compared with patients with radiographic grade 3 or greater (mean 162 days). Plain films were normal despite symptoms in 3 patients in whom MRI subsequently demonstrated osteonecrosis. Diagnosis of osteonecrosis may have been delayed due to several factors including lack of awareness among HIV clinicians of this condition due to the low incidence of osteonecrosis and lack of awareness of HIV-infected patients of this condition. An additional factor for delayed diagnosis may be that pain syndromes are common in patients with HIV and thus both providers and patients may have minimized any musculoskeletal complaints or misdiagnosed them. The delay in the diagnosis of osteonecrosis may result in patients presenting with later stage disease, which in turn may be less amenable to conservative therapy.

Optimal management of osteonecrosis in HIV in terms of diagnosis and treatment is not known, because so few cases have been reported. Physicians treating patients with HIV should have a high index of suspicion for osteonecrosis in patients with pain in one or more joints. If plain films are normal and symptoms of osteonecrosis persist, strong consideration should be given to obtaining a MRI study. Although surgical management of HIVinfected patients with osteonecrosis is beyond the scope of this study, the same principles of management for osteonecrosis in HIV-uninfected patients should be followed. In general, the patients in our series who underwent joint replacement did well. HIV itself should not exclude patients from joint replacement.

\section{CONCLUSIONS}

Incidence of osteonecrosis in our HIV/AIDS clinic population appears to be greater than expected in the general population and the diagnosis of osteonecrosis in HIV was often delayed. Most patients diagnosed with osteonecrosis had one or more risk factors, suggesting that the increased incidence of osteonecrosis in HIV/ AIDS may be due to an increased frequency of risk factors previously associated with osteonecrosis. Use of megesterol acetate may be a new osteonecrosis risk factor. Finally, with the exception of saquinavir, we did not find a definitive association of osteonecrosis with the use of PIs.

\section{REFERENCES}

1. Owings MF, Lawrence L. Detailed diagnoses and procedures. National Hospital Discharge Survey, 1997. National Center for Health Statistics. Vital Health Stat 1999;13(145).

2. Coventry MB, Beckenbaugh RD, Nolan DR, Ilstrup DM. 2,012 total hip arthroplasties. A study of postoperative course and early complications. J Bone Joint Surg Am 1974;56:273-84.

3. Jacobs B. Epidemiology of traumatic and nontraumatic osteonecrosis. Clin Orthop 1978:130:51-67.

4. Mont MA, Hungerford DS. Non-traumatic avascular necrosis of the femoral head. J Bone Joint Surg Am 1995;77:459-74.

5. Chang CC, Greenspan A, Gershwin ME. Osteonecrosis: current perspectives on pathogenesis and treatment. Semin Arthritis Rheum 1996;23:47-69.

6. Jones JP Jr. Osteonecrosis. In Koopman WJ, ed. Arthritis and allied conditions: a textbook of rheumatology, 13th ed. Baltimore: Williams \& Wilkins, 1997:1923-42.

7. Hodak SP, Fluhme D, Kumar P, Nascone J, Evans B, Timpone JG. Avascular necrosis and protease inhibitor exposure. Abstracts of the 39th Interscience Conference on Antimicrobial Agents and Chemotherapy, San Francisco, 1999.

8. Belmonte MA, Garcia-Portales R, Domenech I, Fernandez-Nebro A, Camps MT, De Ramon E. Avascular necrosis of bone in human immunodeficiency virus infection and antiphospholipid antibodies. J Rheumatol 1993;20:1425-8.

9. Chevalier X, Larget-Piet B, Hernigou P, Gherardi R. Avascular necrosis of the femoral head in HIV-infected patients. $J$ Bone Joint Surg Br 1993;75:160.

10. Gerster JC, Camus JP, Chave JP, Koeger AC, Rappoport G. Multiple site avascular necrosis in HIV infected patients. $J$ Rheumatol 1991;18:300-2.

11. Goorney BP, Lacey H, Thurairajasingam S, Brown JD. Avascular necrosis of the hip in a man with HIV infection. Genitourin Med 1990;66:451-2.

12. Olive A, Queralt C, Sirera G, Centelles M, Force L. Osteonecrosis and HIV infection: 4 more cases. J Rheumatol 1998;25:1243-4.

13. Rademaker J, Dobro JS, Solomon G. Osteonecrosis and human immunodeficiency virus infection. J Rheumatol 1997;24:601-4.

14. Stovall D Jr, Young TR. Avascular necrosis of the medial femoral condyle in HIV-infected patients. Am J Orthop 1995;24:71-3.

15. Tigges S, Meli RJ. Osteonecrosis associated with HIV infection. Can Assoc Radiol J 1995;46:280-4.

16. Llauger J, Palmer J, Roson N, Fernandez A, Camins A. Osteonecrosis of the knee in an HIV-infected patient. AJR Am J Roentgenol 1998;171:987-8.

17. Meyer D, Behrens G, Schmidt RE, Stoll M. Osteonecrosis of the femoral head in patients receiving HIV protease inhibitors [letter] AIDS 1999;13:1147-8.

18. Koeger AC, Banneville B, Gerster JC, et al. Avascular osteonecrosis in HIV-infected patients: 10 cases. Arthritis Rheum 1995; 38:S199.

19. Solomon G, Brancato L, Winchester R. An approach to the human immunodeficiency virus-positive patient with a spondyloarthropathic disease. Rheum Dis Clin North Am 1991;17:43-58.

20. Mammen-Prasad EK, Bishburg E. Avascular necrosis in HIV in- 
fected patients. Abstracts of the Infectious Diseases Society of America 37th Annual Meeting, Philadelphia, 1999.

21. Steinberg ME, Hayken GD, Steinberg DR. A quantitative system for staging avascular necrosis. J Bone Joint Surg Br 1995;77:3441.

22. Resnick D, Niwayama G. Osteonecrosis: diagnostic techniques, specific situations, and complications. In Resnick D, ed. Diagnosis of bone and joint disorders, 3rd ed. Philadelphia: WB Saunders, 1995:3495-3558.

23. Leinung $\mathrm{MC}$, Liporace $\mathrm{R}$, Miller $\mathrm{CH}$. Induction of adrenal suppression by megestrol acetate in patients with AIDS. Ann Intern Med 1995;122:843-845.

24. Loprinzi CL. Effect of megesterol acetate on the human pituitaryadrenal axis. Mayo Clin Proc 1992;67:1160-2.

25. Subramanian S, Goker H, Kanji A, Sweeney H. Clinical adrenal insufficiency in patients receiving megesterol therapy. Arch Intern Med 1997;157:1008-11.

26. Padmanabhan S, Rosenberg AS. Cushing's syndrome induced by megesterol acetate in a patient with AIDS. Clin Infect Dis 1998; 27:217-18.

27. Gibert C, Koller E, Mann M, Bacsanyi J, Malozowski S. Avascular necrosis in AIDS patients receiving megestrol acetate. Presented at the 5th Conference on Retroviruses and Opportunistic Infection, Chicago, 1998.

28. Carr A, Samaras K, Thorisdottir A, Kaufman GR, Chisholm DJ,
Cooper DA. Diagnosis, prediction, and natural course of HIV-1 protease-inhibitor-associated lipodystrophy, hyperlipidaemia, and diabetes mellitus: a cohort study. Lancet 1999;353:2093-9.

29. Van Veldhuizen PJ, Neff J, Murphey MD, Bodensteiner D, Skikne BS. Decreased fibrinolytic potential in patients with idiopathic avascular necrosis and transient osteoporosis of the hip. Am J Hematol 1993;44:243-8.

30. Mankin HJ. Nontraumatic necrosis of bone (osteonecrosis). N Engl J Med 1992;326:1473-9.

31. Lafeuillade A, Alessi MC, Poizot-Martin I, et al. Protein S deficiency and HIV infection [letter]. N Engl J Med 1991;324:1220.

32. Stahl CP, Wideman CS, Spira TJ, Haff EC, Hixon GJ, Evatt BL. Protein $\mathrm{S}$ deficiency in men with long-term human immunodeficiency virus infection. Blood 1993;81:1801-7.

33. Cohen AJ, Philips TM, Kessler CM. Circulating coagulation inhibitors in the acquired immunodeficiency syndrome. Ann Intern Med 1985;104:475-80.

34. Canoso RT, Zon LI, Groopman JE. Anticardiolipin antibodies associated with HTLV-III infection. Br J Haematol 1987;65:495-8.

35. Bloom EJ, Abrams DI, Rodgers G. Lupus anticoagulant in the acquired immunodeficiency syndrome. JAMA 1986;256:491-3.

36. Stimmler MM, Quismorio FP Jr, McGehee WG, Boylen T, Sharma OP. Anticardiolipin antibodies in acquired immunodeficiency syndrome [see comments]. Arch Intern Med 1989;149:1833-5. 